\title{
Stratosphere Observation Project Using a Small Balloon
}

\author{
F. Abdullah*, M. Matsuoka, K. Okuyama, A. Hanazawa \\ Department of Applied Science for Integrated System Engineering, Kyushu Institute of Technology, Japan
}

Copyright $\bigcirc 2018$ by authors, all rights reserved. Authors agree that this article remains permanently open access under the terms of the Creative Commons Attribution License 4.0 International License

\begin{abstract}
Global warming continues to be a major concern around the world. The Integrated System Engineering Lab in Kyushu Institute of Technology (KIT) launched a small balloon to the stratosphere to study the ozone layer and greenhouse gases in order to understand global warming. It is a part of the Project Based Learning (PBL) course in KIT. The project mission objectives were to obtain photographs and video of the Earth surface and space and to perform measurement of the ozone gas $\left(\mathrm{O}_{3}\right)$ and carbon dioxide gas $\left(\mathrm{CO}_{2}\right)$ concentration in the atmosphere. The payload was launched into the stratosphere using a small balloon. After the balloon exploded at maximum altitude, the payload descended using a parachute before being recovered at sea. This project was divided into three (3) groups which were the structure, electrical and transmission team. Simulation of the flight path was performed to aid in recovering the payload. The project started from April 2016 and the balloon was successfully launched on October 30, 2016 from Saiki in the Oita prefecture of Kyushu, Japan. This paper will describe the procedure and result of this project.
\end{abstract}

Keywords Space Balloon, Global Warming, Stratosphere, High Altitude Balloon, Greenhouse, Ozone

\section{Background on Global Warming}

Global warming is the increase in the average temperature of planet Earth due to greenhouse gases [1]. The Earth's surface is naturally warmed up by the solar radiation from the sun. About $30 \%$ of the solar radiation gets reflected back to space by clouds, particles in the atmosphere and surface features such as ice and snow [2]. About $20 \%$ is absorbed by molecules in the atmosphere and the remaining $50 \%$ is absorbed by land and oceans which causes the Earth to warm up [2]. At night, heat is released back into space in the form of infrared radiation. Some of this infrared radiation is absorbed by the gases in the atmosphere including the stratosphere and can heat up the Earth's surface once again. These gases are called greenhouse gases. The effect whereby heat is trapped within Earth's atmosphere is called the greenhouse effect [3].

The effect of global warming on Earth is a series of events linked to one another. In general, the increase in temperature will result in severe melting of sea ice in the poles and glaciers. The additional outflow of freshwater will raise sea level globally endangering coastal areas. In addition, increasing temperature will affect the Earth's climate resulting in catastrophic events such as severe drought and excessive flooding [2].

This project aims to measure using specialized gas sensors two major greenhouse gases as listed below:

\section{i Carbon dioxide}

ii Ozone

Carbon dioxide is produced naturally through respiration and is naturally taken away from the atmosphere by plants through the photosynthesis process. Ideally, there is a balance in the amount of carbon dioxide released and absorbed from the atmosphere. Unfortunately, recent human activities of deforestation and burning of fossil fuels have caused an increase in the carbon dioxide concentration in the atmosphere. Deforestation causes fewer trees to absorb the carbon dioxide while burning of fossil fuels released carbon dioxide that was absorbed by trees millions of years ago. Historically carbon dioxide concentration in the atmosphere is around 180 parts per million (ppm) to $300 \mathrm{ppm}$. Lately, carbon dioxide concentration has increased to nearly $400 \mathrm{ppm}$ [2].

Naturally, ozone exists in the stratosphere region to absorb harmful ultraviolet (UV) rays. Ozone is formed from oxygen molecules through photodissociation by the UV rays [4]. Ozone can also be a greenhouse gas if found in the lower part of the atmosphere. The chemical reactions of nitrous oxide with nitrogen oxides results in the release of ozone near the Earth's surface [2]. This results in increased temperature near the ground.

\section{Project Overview}

This project aims to study the ozone layer and the Carbon Dioxide $\left(\mathrm{CO}_{2}\right)$ greenhouse gas in the stratosphere using a small balloon or high altitude balloon (HAB). The 
title of this project is "Stratosphere Observation Project Using a Small Balloon" or "Space Balloon Project". The project is also part of the Project Based Learning (PBL) course. The objective of the PBL course is to train students in solving complex real-world problems as a team.

\subsection{Mission Objectives}

The project mission objectives are listed below:

i To obtain video of the Earth's surface and space.

ii To perform in-situ measurement for the concentration of Ozone $\left(\mathrm{O}_{3}\right)$ and Carbon Dioxide $\left(\mathrm{CO}_{2}\right)$ gas in the stratosphere.

\subsection{Team Structure}

The structure of the project team is illustrated in Table 1.

Table 1. Project Team Structure and Function

\begin{tabular}{|c|ll|}
\hline Group & \multicolumn{2}{|c|}{ Function } \\
\hline \multirow{3}{*}{ Structure } & i & $\begin{array}{l}\text { Construct parachute } \\
\text { ii }\end{array}$ \\
& iii & $\begin{array}{l}\text { Construct payload structure } \\
\text { Develop connection methods between } \\
\text { payload, parachute and balloon }\end{array}$ \\
\hline \multirow{3}{*}{ Electrical } & i & Programming of sensors \\
& ii & Construct the circuit board \\
& iii & Develop data recording device \\
& iv & Camera operations \\
\hline \multirow{2}{*}{ Communication } & i & Develop tracking device \\
& ii & Develop the ground station \\
\hline
\end{tabular}

\subsection{Flight Plan}

The flight profile of the HAB started with the launch of the balloon on 30/10/2016 from Saiki in the Oita prefecture in Kyushu, Japan. The balloon will then ascend to $20 \mathrm{~km}$ before it bursts. The payload will then descend to the sea using a parachute. The estimated landing spot is near the Kochi prefecture in Shikoku, Japan. The flight duration is estimated to be approximately 2 hours 20 minutes.

\section{System}

\subsection{Structure System}

The payload structure is one of the major components in the balloon system shown in Figure 1. The purpose of the structure is listed below:

- To protect the payload from the external environment such as low temperature.

- $\quad$ To protect the payload from being damaged during launch and recovery.

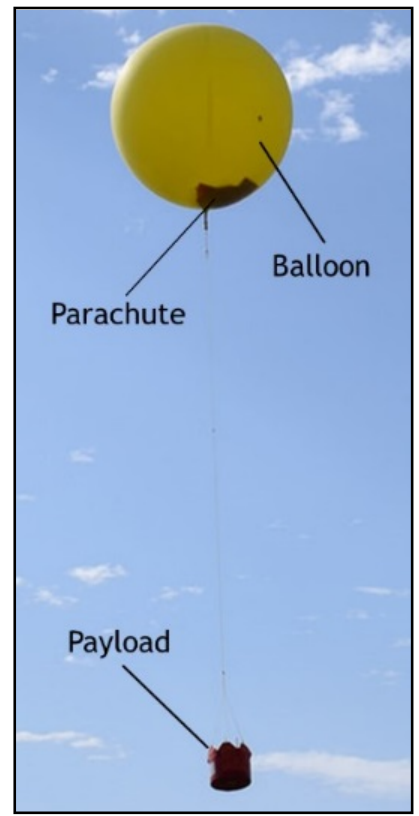

Figure 1. HAB System

The overview of the structure system is illustrated in Figure 2.

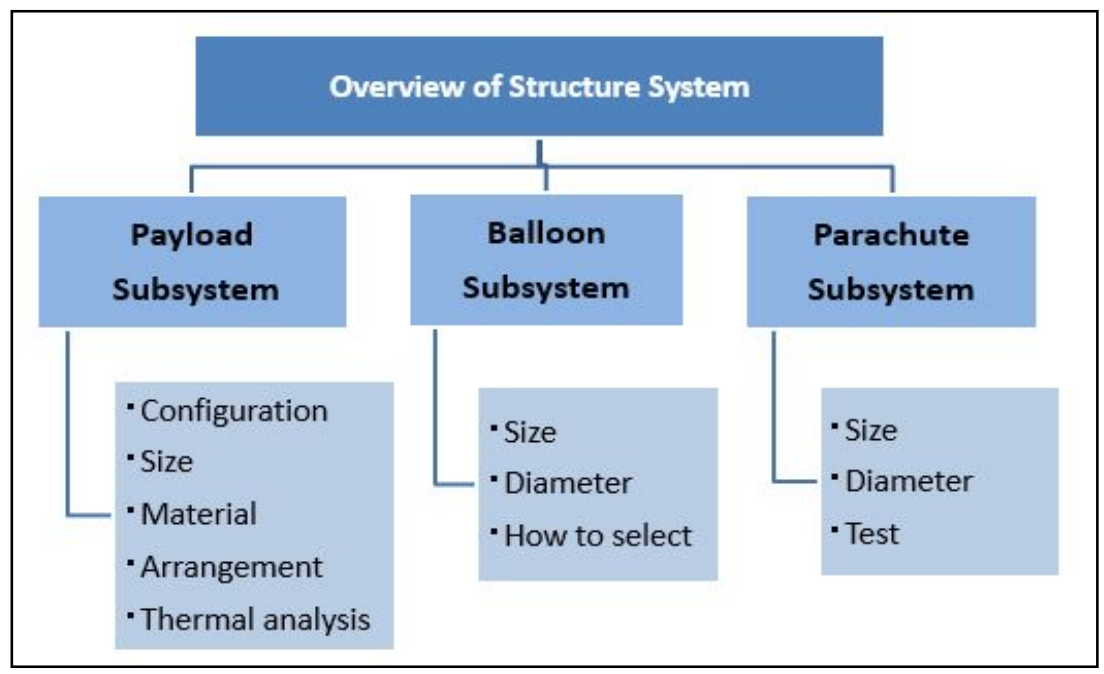

Figure 2. Overview of Structure System 


\subsubsection{Payload Subsystem}

The payload subsystem consisted of the primary structure, secondary structure, and the acrylic windows.

The primary structure is made up of the main body and top cover. During the ascend and descend phase, the structure will be exposed to different horizontal wind speeds [5]. The wind may cause the structure to swing or spin during flight. This may introduce unstable video images, disrupt data collection, and may stress the connection points between the structure, parachute and balloon. One way to reduce wind disturbance is by designing a structure with minimum drag. In the case of this project, the structure was cylindrical in shape due to a lower drag coefficient compared to a cube for the same parameter i.e. velocity, cross-sectional area and air density $[6,7]$. As a result, the wind resistance for a cylinder shape structure was lower compared to a box shape structure. This can decrease possible swinging and spinning motion. The various layers of the atmosphere resulted in varying atmospheric temperature between $20^{\circ} \mathrm{C}$ to $-60^{\circ} \mathrm{C}$. Most of the electrical components have limited operating temperature. In order to maintain a stable and suitable temperature for the electrical components, the structure has a maximum thickness of $5 \mathrm{~cm}$ for the top cover and $6 \mathrm{~cm}$ for the bottom part of the main body. The thickness of the side wall is $4.5 \mathrm{~cm}$. In addition, the thick lower part of the main body acted as shock absorbers during landing. This is to minimize potential damage to the structure and the payload.

The secondary structure comprises the platform and sensor box. The platform was used to mount some of the electrical components such as the Arduino board and the pressure sensor. The sensor box was used to protect the ozone and carbon dioxide gas sensors. The sensors reading can be affected by strong wind. As such the casing was used to limit the exposure of the sensors to strong wind.

There were three types of camera window for three camera positions which were at the top cover, side wall and bottom part of the main body. Each camera window was covered with a piece of acrylic sheet. The purpose of the camera window was to secure the camera during flight and to protect the camera from cold air and water. Anti-condensation spray was sprayed on the acrylic sheet to avoid condensation on the camera lens due to varying temperatures.

The assembled structure has an outer diameter of $32 \mathrm{~cm}$ with a total height of $23 \mathrm{~cm}$. The wall thickness is $4.5 \mathrm{~cm}$. The total mass of the structure is $0.26 \mathrm{~kg}$. Figure 3 illustrates the exploded view of the whole payload structure.

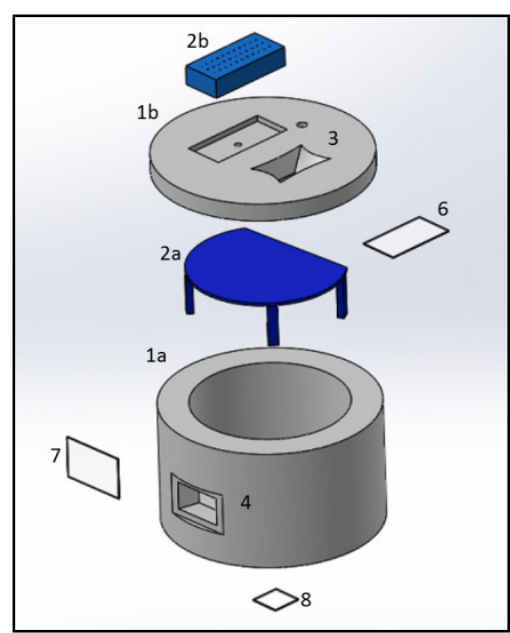

Figure 3. Payload Structure Assembly

The corresponding parts based on Figure 3 are listed below:

1. Primary structure:

a. Main body

b. Top cover

2. Secondary structure:

a. Platform

b. Sensor box

3. Top window

4. Side window

5. Bottom window

6. Top acrylic window

7. Side acrylic window

8. Bottom acrylic window

The primary structure was constructed of expanded polystyrene (EPS) material as shown in Figure 4. The justification for selecting EPS was due to the following reasons:

i Lightweight mass.

ii Strong and durable.

iii Low thermal conductivity.

iv Waterproof properties.

v Easy to work with in terms of cutting and shaping.

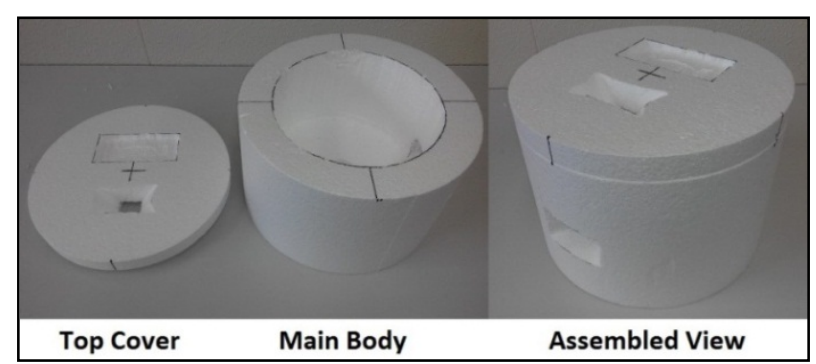

Figure 4. Completed Primary Structure 
The platform was made from $5 \mathrm{~mm}$ thick foam board. The sensor box was constructed using a three-dimensional (3D) printing method. There were thirty-three holes on the upper surface, each with a diameter of $2 \mathrm{~mm}$. The holes were designed to allow a limited amount of air to enter the box for sensor reading.

\subsubsection{Thermal Control of Payload Subsystem}

The thermal control system is important to ensure that the onboard electrical system operates within the specified operating temperature. The primary heat source for the balloon system comes from the onboard electrical system. Heat flows from an area with high temperature to a lower temperature area. In the case of the balloon flight, the heat was transferred from inside to outside in two steps. Firstly, the heat was released from the onboard electrical system through radiation. Secondly, the heat was then transferred out through the walls of the structure via conduction.

There were two passive thermal control components to counter the heat loss via radiation and conduction for this project as listed below:

$i$ Usage of polystyrene as the material for the primary structure. Polystyrene is a good insulator against low temperature.

ii Usage of polyester film with aluminum vacuum deposition coating to cover the inner surface of the payload structure. The polyester film has a reflectivity ranging from $90 \%$ to $98 \%$ compared to white polystyrene with a reflectivity of approximately $66 \%[8,9]$. The higher reflectivity of the polyester film is useful for reflecting heat from the electrical system that may otherwise escape outside through radiation. Figure 5 illustrates the inner part of the main body and lower part of the top cover covered with the polyester film.

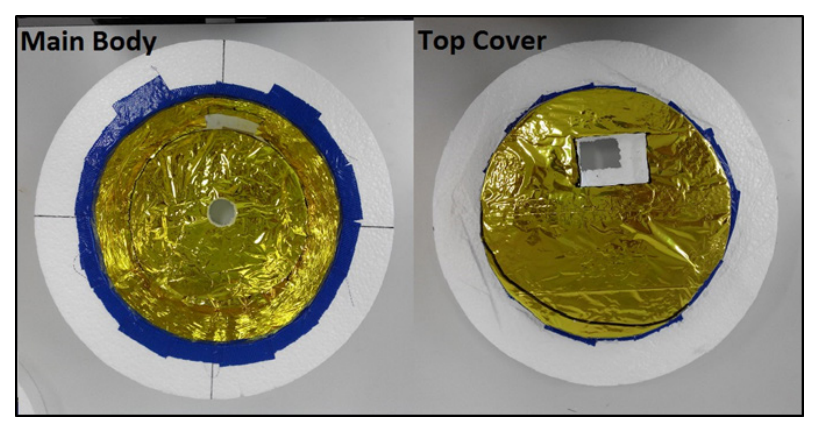

Figure 5. Polyester Film for Main Body and Top Cover

The structure was tested in a low-temperature environment using a freezer. The purpose of the test was to determine the effectiveness of the thermal control system. The freezer can simulate an environment with the lowest temperature of approximately $-20^{\circ} \mathrm{C}$. This is analogous to a high-altitude environment.
A thermal analysis of the structure was also performed using Systems Improved Numerical Differencing Analyzer (SINDA) thermal analysis software. The objective of the analysis was to develop a thermal model to predict the internal temperature during the actual flight. Initially, a thermal model was developed to simulate the test environment during the temperature test in the freezer. Over the course of the project, minor changes were introduced to the electrical system. As a result, the initial thermal model was enhanced to accommodate these changes and to simulate the actual flight conditions. Table 2 illustrates the average internal temperature for all three (3) tests.

Table 2. Average Internal Temperature for Different Type of Test

\begin{tabular}{|c|l|c|}
\hline No & \multicolumn{1}{|c|}{ Type of Test } & $\begin{array}{c}\text { Average Internal } \\
\text { Temperature }\end{array}{ }^{\circ} \mathbf{C}$ \\
\hline 1. & Temperature test in freezer & 23.72 \\
\hline 2. & Initial Thermal analysis in SINDA & 22.68 \\
\hline 3. & $\begin{array}{l}\text { Thermal analysis in SINDA in flight } \\
\text { conditions }\end{array}$ & 8.55 to 18.04 \\
\hline
\end{tabular}

The analysis showed that the thermal control system for the structure could maintain a suitable temperature for the operation of the onboard electrical system.

\subsubsection{Balloon Subsystem}

A latex balloon was used to lift the payload to the stratosphere. The balloon floated upwards based on the principle of buoyancy. For a balloon to float, it needs to be filled with gas that is less dense than air such as helium or hydrogen. This project uses helium. The specification of the balloon and the flight parameters were estimated using the Totex Balloon Burst Estimator developed by Steve Randall [10]. The burst estimator allows the user to adjust the launch diameter, balloon mass, and payload mass. By increasing the launch diameter, the balloon has a larger initial volume. As a result, the balloon can only float to a lower altitude before bursting with a restricted burst diameter. On the other hand, lowering the initial launch diameter will allow the balloon to reach higher altitudes before bursting. In terms of ascent rate, an increase in the volume of helium during launch will result in a higher ascent rate. Consequently, the time to burst and the total flight duration will decrease. A lower initial volume of helium will result in a lower ascent rate, longer time to burst and total flight duration.

The main inputs for the estimator were the balloon mass, the payload mass, and the launch diameter. The output was the volume of gas at launch, predicted burst altitude, predicted ascent rate and time to burst. The actual balloon used in this project was a yellow rubber balloon with a mass of $455 \mathrm{~g}$ filled with helium gas. Figure 6 illustrates the balloon used for this project. 

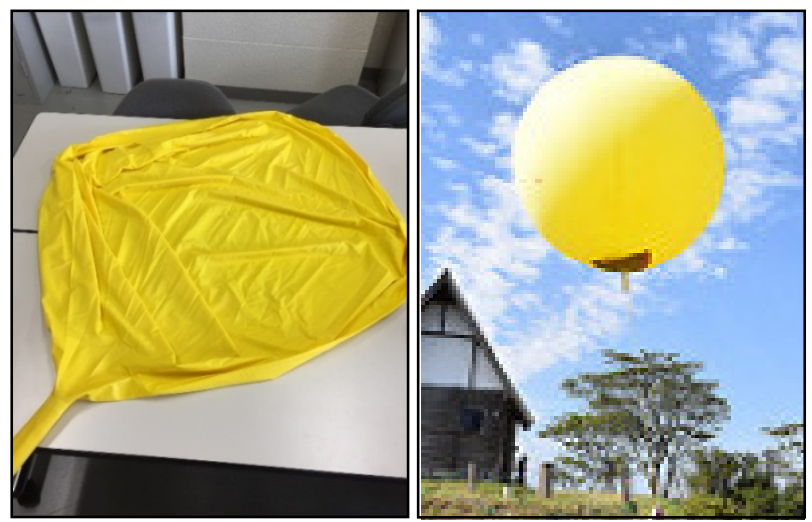

Figure 6. Deflated and Inflated Shape of Balloon

Since the balloon estimator is based on Kaymont Totex Sounding Balloon Data, the nearest balloon mass to the balloon used in the project was $450 \mathrm{~g}$. Table 3 illustrates values used for this project.

Table 3. Actual Input and Estimated Ouput based on Totex Balloon Burst Estimator

\begin{tabular}{|c|c|c|c|}
\hline \multicolumn{2}{|c|}{ Input } & \multicolumn{2}{c|}{ Output } \\
\hline Field & Value & Field & Value \\
\hline Payload Mass $(\mathrm{g})$ & 2,010 & Burst Altitude $(\mathrm{m})$ & $20,933.64$ \\
\hline Balloon Mass $(\mathrm{g})$ & 450 & Ascent Rate $(\mathrm{m} / \mathrm{s})$ & 4.15 \\
\hline Launch Diameter $(\mathrm{m})$ & 1.8 & Time to Burst $(\mathrm{min})$ & 83.99 \\
\hline & & Volume at launch $\left(\mathrm{m}^{3}\right)$ & 3.05 \\
\hline
\end{tabular}

\subsubsection{Parachute Subsystem}

The recovery system for the payload is a parachute. The main purpose of the parachute is to decrease the descent velocity of the payload. This can minimize the risk of damage to the payload during landing. During the descending phase, the parachute will be subjected to an upward drag force that will exert pressure on the parachute material and expand it. At the same time, the parachute will be pulled downwards by the weight of the payload and the parachute itself.

Designing the parachute involved tradeoffs such as between recovery distance and protection to the payload. A slower descent velocity can decrease the risk of damage to the payload during landing but may result in the payload drifting further due to the wind. As a result, the tracking process may become challenging due to increased recovery distance. For this project, the payload was predicted to land on water thus a higher descent velocity was acceptable since water is less dense compared to solid ground. The amount of drift may decrease thus simplifying the recovery process.

A parachute can be constructed in many different shapes with different properties. For this project, the parachute has a hemispherical profile shape when fully inflated.
During descend, incoming air creates a buildup of pressure underneath the parachute canopy. Since there is no hole under the canopy, air will flow to the side of the canopy before escaping out. This air flow will push the parachute to one side resulting in an oscillating motion or swinging. One method to reduce the oscillation is to cut a small vent or spill hole at the apex of the canopy which allows better air flow and a stable descent [11].

An Excel $^{\mathrm{TM}}$ based parachute size calculator was developed to estimate the size of the parachute. The calculator assumes a steady descend with no wind disturbance resulting in the drag force being equal to the weight and a steady descent velocity. There were two constraints. Firstly, the initial total mass of the parachute, payload, structure and other related parts was $1.8 \mathrm{~kg}$. Secondly, the maximum nominal diameter was $1.53 \mathrm{~m}$ due to the maximum width of $1.54 \mathrm{~m}$ for the available silnylon sheet minus a margin of $0.01 \mathrm{~m}$. Considering the two (2) constraints, Table 4 list the parachute specification.

Table 4. Parachute Specification

\begin{tabular}{|c|c|}
\hline Output & Value \\
\hline Nominal diameter, $\mathrm{d}_{0}$ & $1.53 \mathrm{~m}$ \\
\hline Inflated diameter, $\mathrm{d}_{\mathrm{p}}$ & $1.09 \mathrm{~m}$ \\
\hline Spill hole diameter, $\mathrm{d}_{\mathrm{h}}$ & $0.11 \mathrm{~m}$ \\
\hline Length of parachute line, $\mathrm{L}$ & $2.30 \mathrm{~m}$ \\
\hline
\end{tabular}

The main material for the parachute was silnylon. It is durable, lightweight and is waterproof. The strings for the parachute line were made of nylon. Nylon is light and strong compared to normal cotton strings. The connection point between the strings and the parachute consisted of a square piece of tarpaulin sewed at the connection point, duct tape to secure the thread, cable tie, and metal ring. Figure 7 and 8 illustrates the string connection method and the completed parachute.

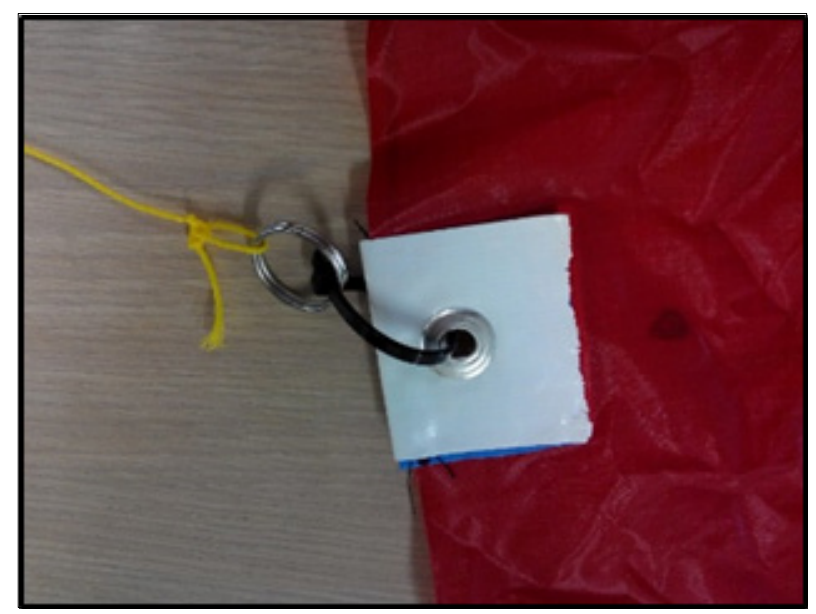

Figure 7. String Connection Method 


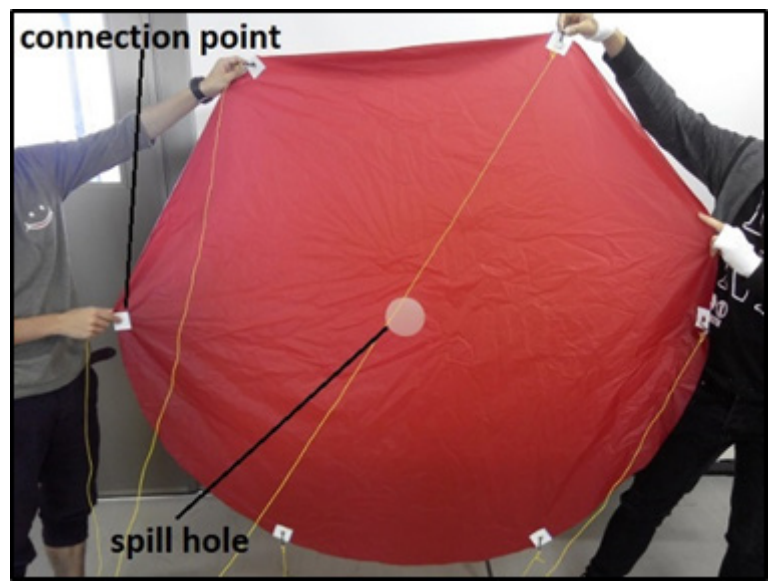

Figure 8. Completed Silnylon Parachute

Four drop tests were carried out using different parachute sizes including the final parachute size. In the drop test, the parachute attached to the payload was dropped off from the rooftop of a building. The overall objective of the drop test was to test the design of the parachute, the connection method between the parachute and the structure and to calculate the descent velocity.

Overall, the four tests proved the feasibility of the designed parachute and connection system. However, a discrepancy in value was discovered between the theoretical and experimental descent velocity due to the following factors: -

i The assumed drag coefficient, $C_{d}$ value of 0.75 was different from the test value of 2.82 .

ii The assumed ratio between $\mathrm{d}_{\mathrm{p}}$ and $\mathrm{d}_{0}$ was different from the test value.

iii The parachute size calculator assumes a steady ascend whereby equilibrium was achieved between drag force and weight. However, the low elevation of the release point did not allow sufficient time for the parachute to achieve an equilibrium condition with zero acceleration.

iv The parachute size calculator does not consider windy conditions which can affect the descent velocity.

\subsection{Electrical System}

The payload is the electrical system which comprised of various electrical components each with its own unique function. The main objective of the electrical system is listed below:

i To acquire data regarding the concentration of ozone gas $\left(\mathrm{O}_{3}\right)$ and carbon dioxide gas $\left(\mathrm{CO}_{2}\right)$ concentration in the atmosphere.

ii To acquire the picture of space.

The overview of the structure system is illustrated in Figure 9.

\subsubsection{Sensor Subsystem}

The function of the sensor subsystem was to record data regarding the internal temperature, external pressure, $\mathrm{O}_{3}$ gas concentration, $\mathrm{CO}_{2}$ gas concentration, position and altitude of the balloon and payload. Off the shelf components were selected to reduce cost and to increase reliability. Table 5 lists the function of the sensors.

Table 5. Function of Major Sensors

\begin{tabular}{|c|c|}
\hline Sensor & Function \\
\hline Ozone & Measure $\mathrm{O}_{3}$ gas concentration \\
\hline Carbon dioxide & Measure $\mathrm{CO}_{2}$ gas concentration \\
\hline Pressure & $\begin{array}{c}\text { Measure altitude and internal } \\
\text { temperature }\end{array}$ \\
\hline $\begin{array}{c}\text { Global Positioning System } \\
\text { (GPS) }\end{array}$ & $\begin{array}{c}\text { Measure position and altitude of } \\
\text { balloon and payload }\end{array}$ \\
\hline
\end{tabular}

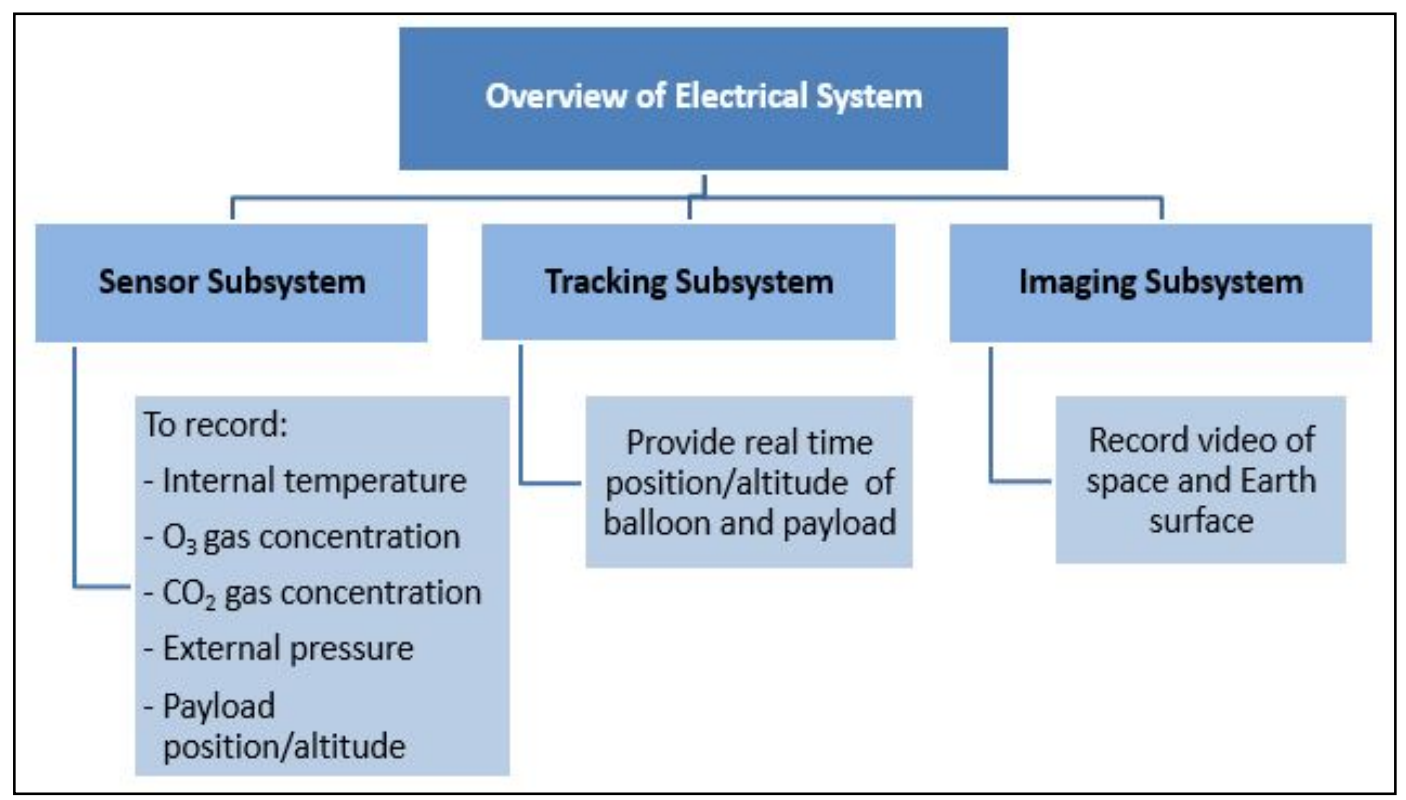

Figure 9. Overview of Electrical System 
The data from the sensors were recorded on a micro SD card through a micro SD card reader. The sensors and the micro SD card reader were controlled by a single onboard processor which is the Arduino Uno R3. The sensor subsystem was powered by two (2) $9 \mathrm{~V}$ alkaline batteries. The completed circuit for the sensor subsystem is illustrated in Figure 10.

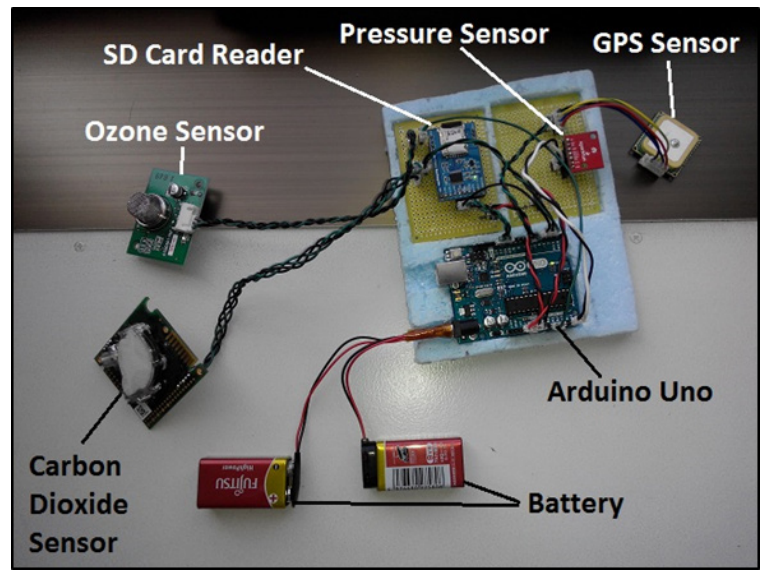

Figure 10. Completed Circuit for Sensor Subsystem

\subsubsection{Tracking Subsystem}

Tracking is essential in determining the current position of the balloon and to assist in locating the payload during recovery. For this project, the Automatic Packet Reporting System (APRS) tracking method was used to track the balloon and payload. APRS allows real-time communication of the balloon and payload position within a large network of ground stations [12].

The onboard GPS receiver receives a signal containing the coordinate of the payload from GPS satellites. The signal is then processed by the Terminal Node Controller (TNC) for transmission by the transceiver to the ground station. Various ground stations are connected to the APRS network. If a ground station picks up the signal from the balloon/payload, it will update the position on the online map at Google Map APRS (https://aprs.fi). The map was then used by the mobile ground station and the recovery team to narrow down the landing area of the payload. Figure 11 illustrates the flow of the tracking subsystem and real-time video for the imaging subsystem since both utilized the same mobile ground station.

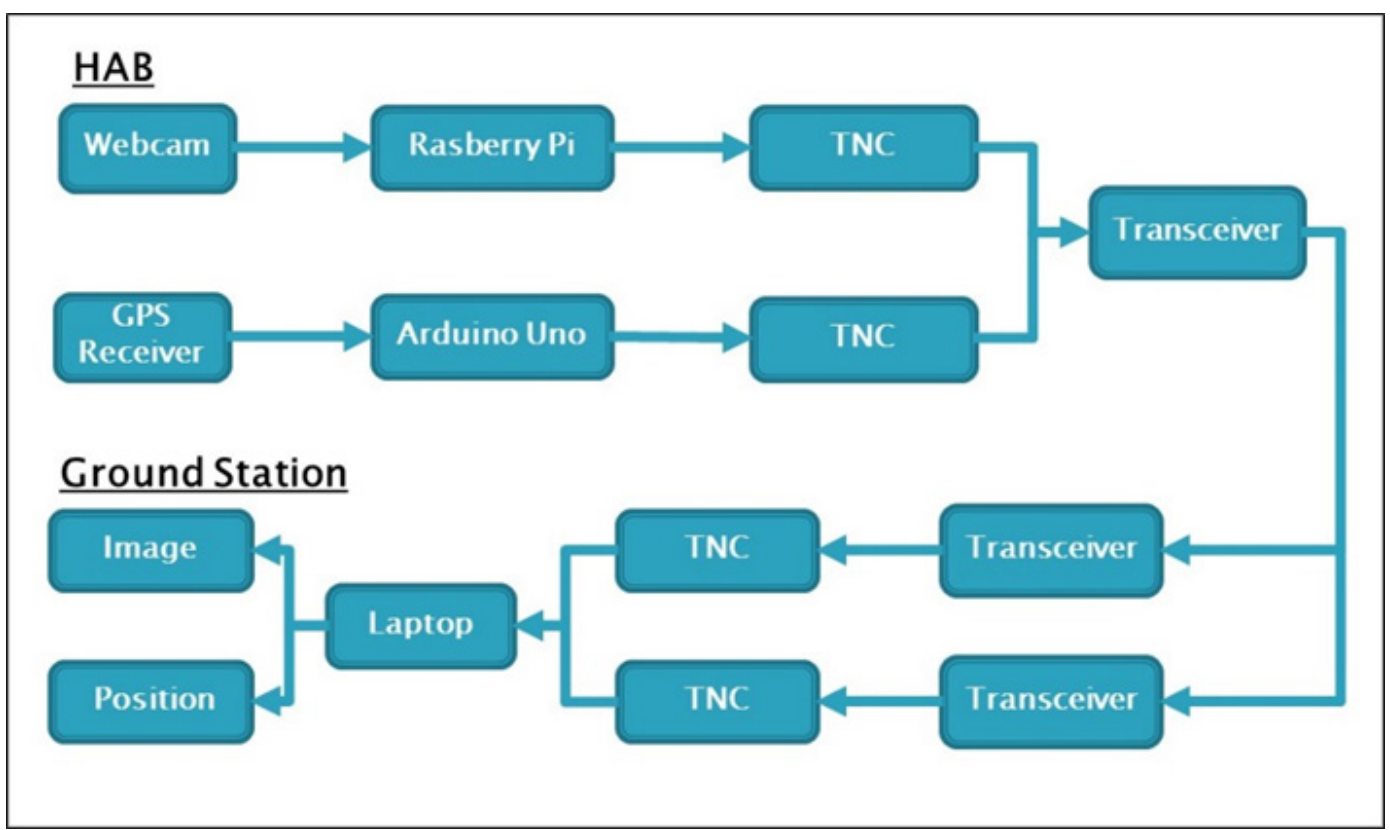

Figure 11. Tracking System and Real Time Video Flow 
The main function of the mobile ground station was to receive the signal from the payload and to assist the recovery team in recovering the payload. There were two mobile ground stations with one set up near the launch location and the other one carried by the recovery team. Each mobile ground station mainly consisted of the transceiver, TNC, laptop and Yagi antenna. Figure 12 illustrates the setup of the ground station near the launch location.

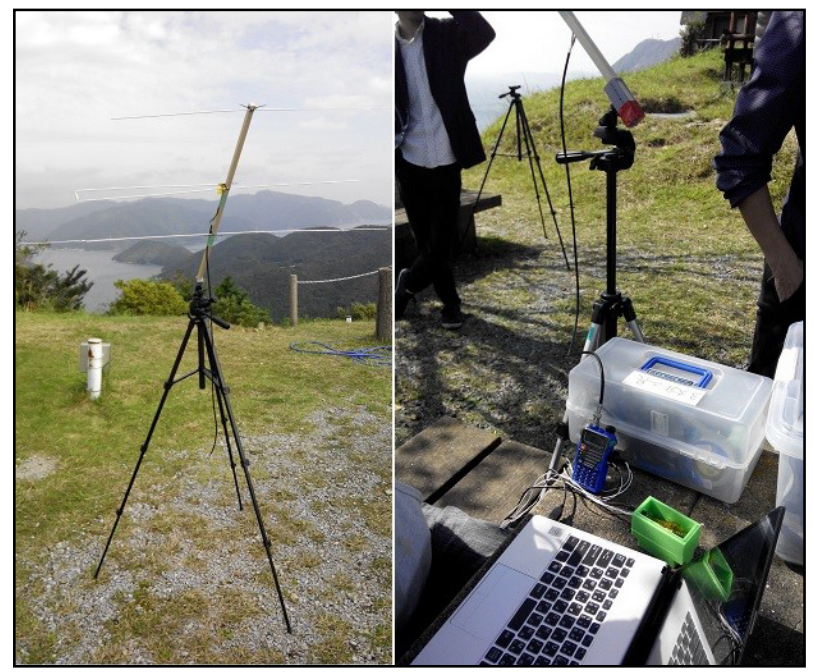

Figure 12. Mobile Ground Station Setup

\subsubsection{Imaging Subsystem}

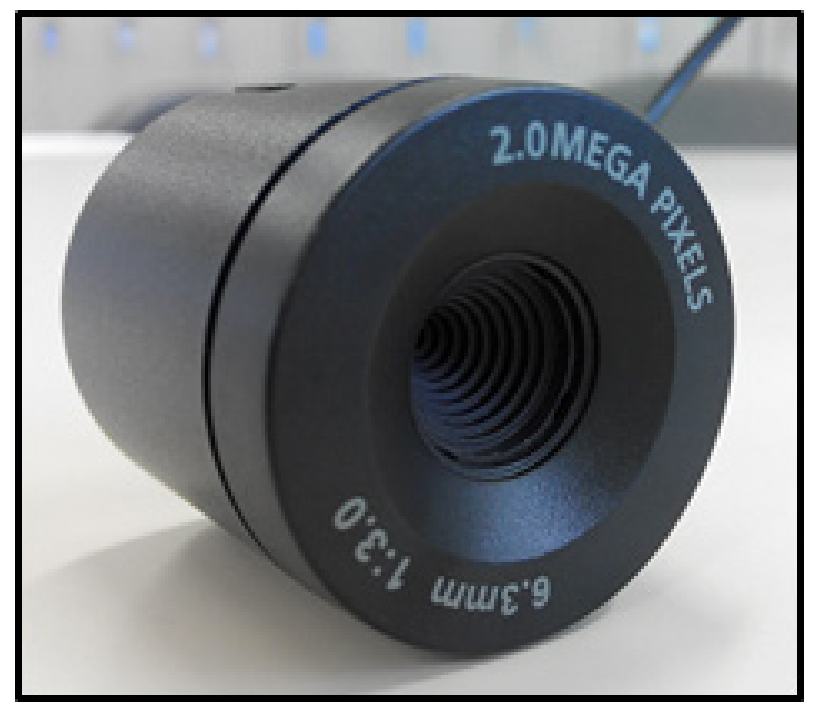

Figure 13. Web camera for Real Time Video

The imaging subsystem was divided into two types. The first type utilized one webcam to record and transmit real-time video from the payload to the ground station. Figure 13 illustrates the webcam used for this project.

The second type utilized two High Definition (HD) cameras to record video of the flight. Figure 14 illustrates the HD camera used for this project.

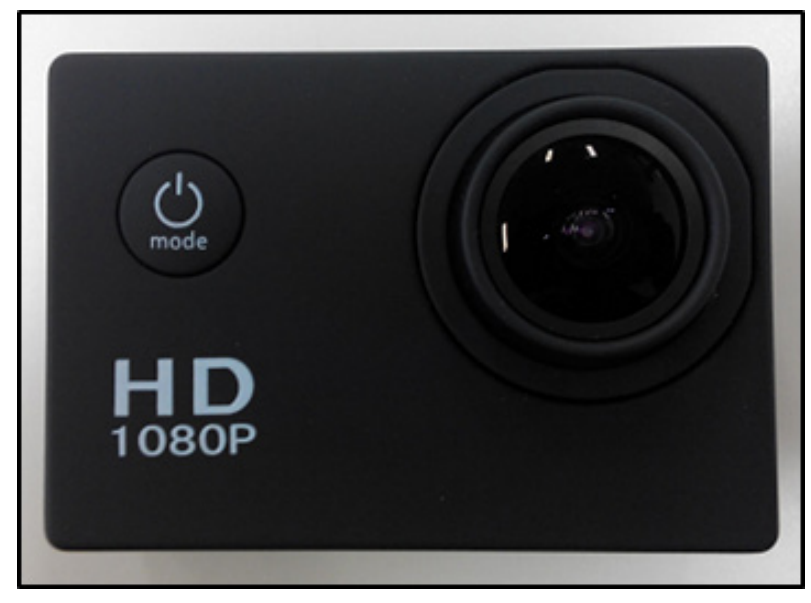

Figure 14. Sports Camera HD

The two (2) HD cameras were positioned in the top cover and the side wall while the webcam was in the bottom part of the payload structure. The top camera provided video of the balloon burst sequence. The side camera provided video of the whole flight in general. Videos from the top and side camera were stored in micro SD cards. The bottom camera provided a real-time video of the whole flight which was transmitted to the ground station.

\section{Flight Simulation}

Flight simulation involved the prediction of the balloon and payload flight path. This step is crucial in planning the logistics for tracking and recovery operations. This project used the Cambridge University Spaceflight (CUSF) Landing Predictor available at http://predict.habhub.org. The prediction tool displays the predicted flight path and the estimated recovery point based on the launch coordinates, ascent velocity, descent velocity, burst altitude, and time. Figure 15 illustrates the overall relationship between the estimated recovery location and the various variables for the balloon and payload. Based on Figure 15, electrical system mass, payload structure mass, and parachute mass are the basic variables that affect the estimated recovery location. Each group in the project contributes towards the prediction of the estimated recovery location by determining the mass of the basic variables. The electrical and communication group determines the mass of the electrical system while the structure group determines the structural and parachute mass. The tool took into account the forecasted weather patterns and jet stream pattern. Several predictions based on a range of burst altitudes were performed before the launch day. This allows the recovery team to estimate the area of recovery and to make the necessary preparations. The accuracy of the prediction tool increased when the launch day approaches due to changing weather patterns. 


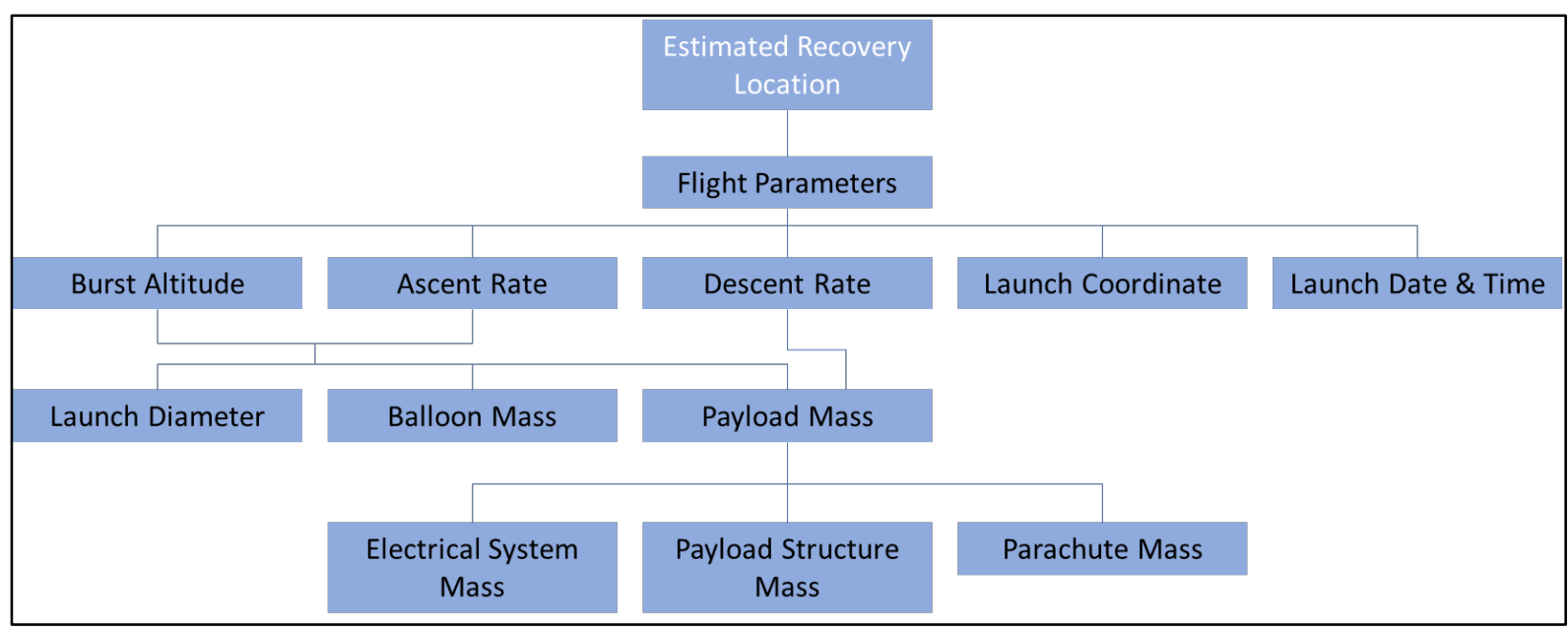

Figure 15. Overall Relationship between Estimated Recovery Location and Project Variables

Figure 16 illustrates a screenshot of the predicted flight path during launch day based on an ascent velocity of $4.15 \mathrm{~m} / \mathrm{s}$, burst altitude of $20,000 \mathrm{~m}$ and descent velocity of $6.0 \mathrm{~m} / \mathrm{s}$. Initially, the ascent velocity and burst altitude were obtained from Table 3. The descent velocity was different than the expected descent velocity in section 3.1.4 to compensate for factors such as actual parachute drag coefficient and weather conditions. The burst altitude was adjusted to provide an acceptable estimated recovery area within the constraint of the available logistics.

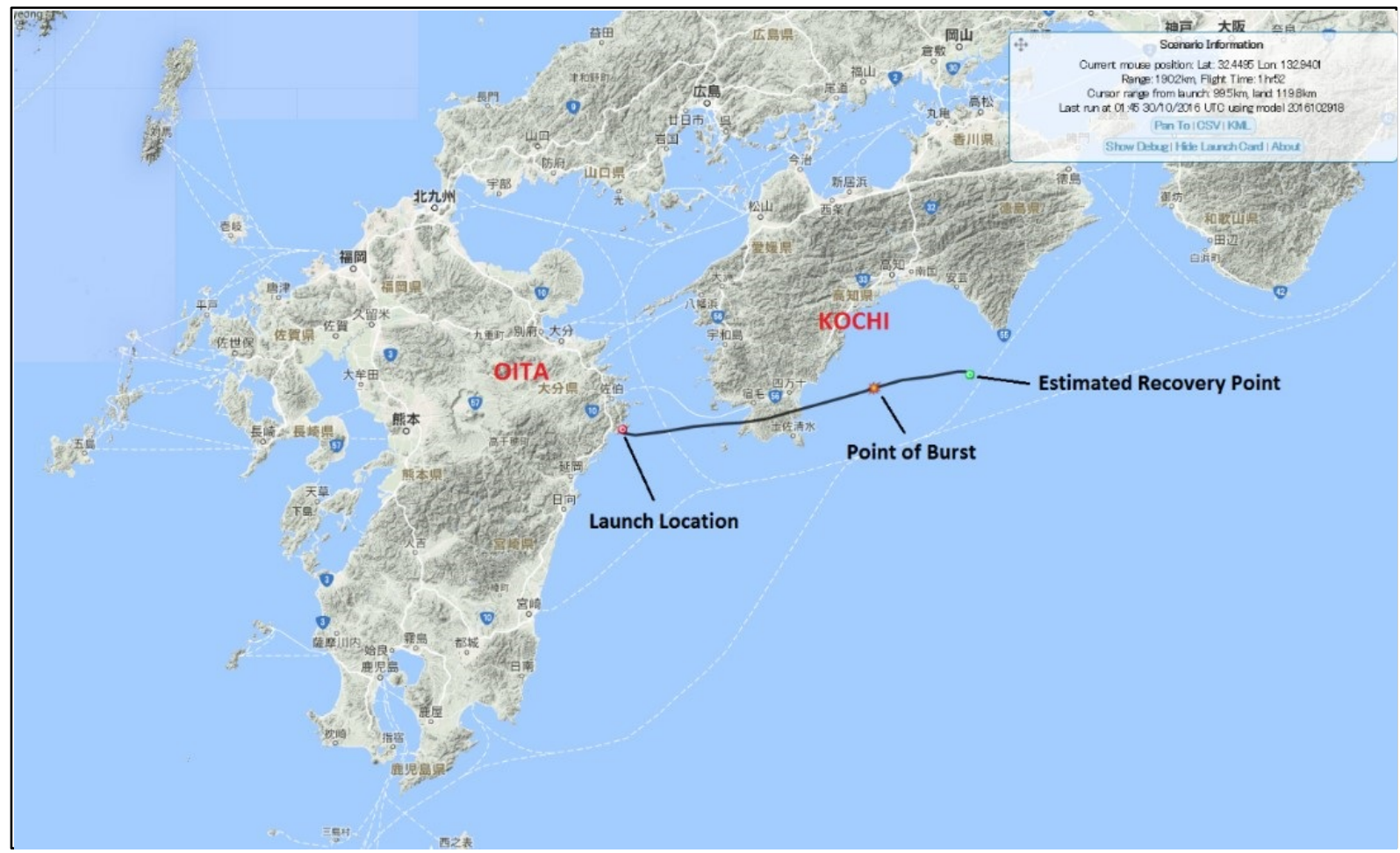

Figure 16. Predicted Flight Path on Launch Day 


\section{Mission Operation}

Mission operation comprised pre-launch preparation and launch day activities.

\subsection{Pre-Launch Preparation}

The pre-launch preparation was divided into four parts as listed below:

$\begin{array}{ll}\text { i } & \text { Documentation } \\ \text { ii } & \text { Team assignment } \\ \text { iii } & \text { Pre-launch checklist } \\ \text { iv } & \text { Flight path prediction }\end{array}$

The documentation part involved three administrative issues that were required to be solved before launch. The issues were listed below:

i To seek permission to use the airspace for the balloon flight. Among the information requested were three possible launch sites, launch date and the maximum altitude.

ii To seek permission to use the launch area for two to three hours. This is to allow sufficient time for completion of the launch operations.

iii To subscribe to a liability insurance. The insurance was meant to compensate for damages in the case of an accident that affect the public safety.

In terms of team assignment, the project team members were divided into two groups for efficient operations; launch and release team and recovery team. The launch and release team was responsible for preparing and launching the balloon and payload and to set up and run the mobile ground station. The recovery team was responsible to search and recover the payload after landing. Both teams will have members to monitor the real-time position of the payload.

Prior to launch day, the following major items were prepared:

i Schedule of tentative activity before and after launch.

ii Procedure manual during launch day.

iii Item checklist for the launch and recovery team.

In addition, a label containing the return address and group representative contact number was pasted to the side of the payload structure. The label is important in the event the payload goes missing during landing. The label can provide the necessary return information to the person who discovers the payload.

The flight path prediction of the balloon and payload was performed several times before and on the launch day. Details about flight path prediction have been discussed previously in section 4 .

\subsection{Launch Day}

The following procedure was implemented during the launch day starting with item i:

i Parachute placement

ii Final assembly of payload and payload structure

iii Inflation of balloon with helium gas

iv Launch of balloon

v Tracking and recovery

In terms of parachute placement, the parachute was rolled up and inserted into the uninflated balloon through the balloon neck as illustrated in Figure 17. By placing the parachute in the balloon, entanglement of the parachute line with the balloon fragment after burst can be avoided.

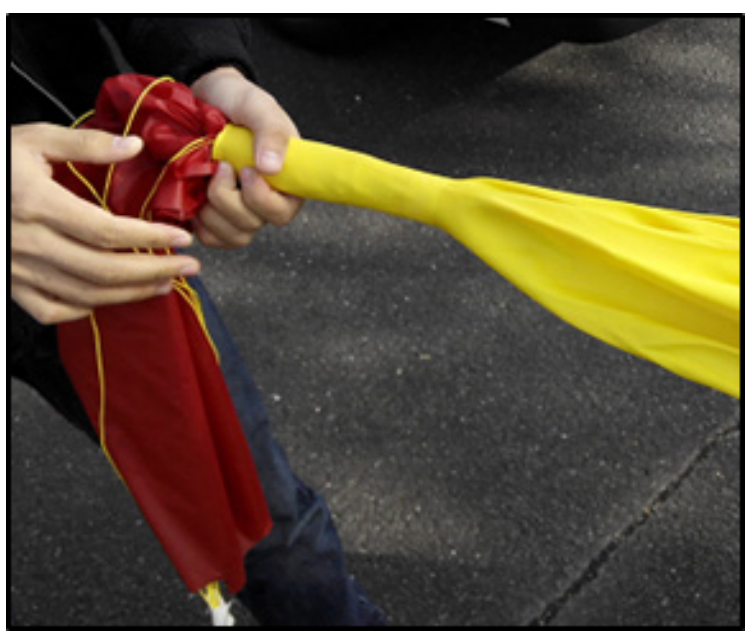

Figure 17. Insertion of Parachute into Balloon

Figure 18 illustrates the placement of electrical components inside and outside of the payload structure.

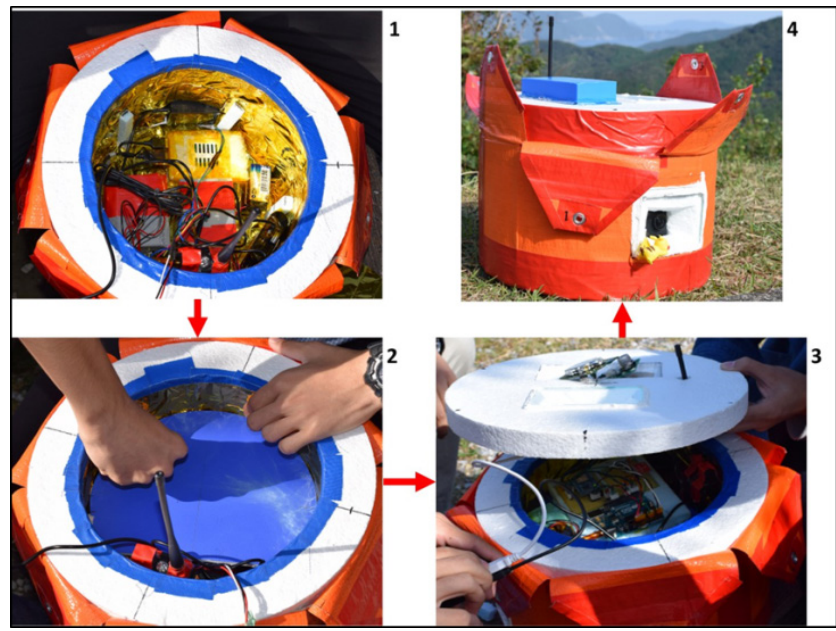

Figure 18. Assembly of Payload Structure and Electrical Components

Prior to filling the balloon with helium, it is important to determine the volume of helium and launch diameter needed to reach $20 \mathrm{~km}$ in altitude. Both parameters were described in section 3.1.3. For this project, the volume of helium required was $3.05 \mathrm{~m}^{3}$ and the launch diameter was $1.8 \mathrm{~m}$.

After connecting the payload structure to the balloon, 
setup of the mobile ground station and confirmation of readiness from all members, a countdown to launch was performed before the final release of the balloon. Tracking was performed with reference to the current payload position displayed on the Google APRS. Figure 19 illustrates the position of the balloon system during the flight.

\section{Result}

The payload was not successfully recovered. The only available data were the location and altitude data acquired using APRS communication up to the last point of contact. Table 6 compares the actual and predicted performance figures for the balloon flight. The differences between actual and predicted performance will be further discussed in two (2) sections; location and altitude.
Table 6. Comparison between Predicted and Actual Performance

\begin{tabular}{|c|c|c|}
\hline Item & Predicted Data & Actual Data \\
\hline Ascent velocity & $4.15 \mathrm{~m} / \mathrm{s}$ & $2.60 \mathrm{~m} / \mathrm{s}$ \\
\hline Descent velocity & $6.00 \mathrm{~m} / \mathrm{s}$ & $5.00 \mathrm{~m} / \mathrm{s}$ \\
\hline Flight duration & 1 hour 50 minutes & 2 hours 20 minutes \\
\hline Burst altitude & $20 \mathrm{~km}$ & $12 \mathrm{~km}$ \\
\hline
\end{tabular}

\subsection{Location}

The initial flight path predicted was shown in Figure 16 based on the ascent velocity of $4.15 \mathrm{~m} / \mathrm{s}$. After launch, another flight prediction was made with an ascent velocity of $2.6 \mathrm{~m} / \mathrm{s}$. The change in ascent velocity was to reflect the average ascent velocity obtained from APRS data which was $2.6 \mathrm{~m} / \mathrm{s}$. The new prediction mirrors the flight path based on APRS data. The last point of contact was approximately at $2,500 \mathrm{~m}$ above sea level due to loss of signal as illustrated in Figure 19.

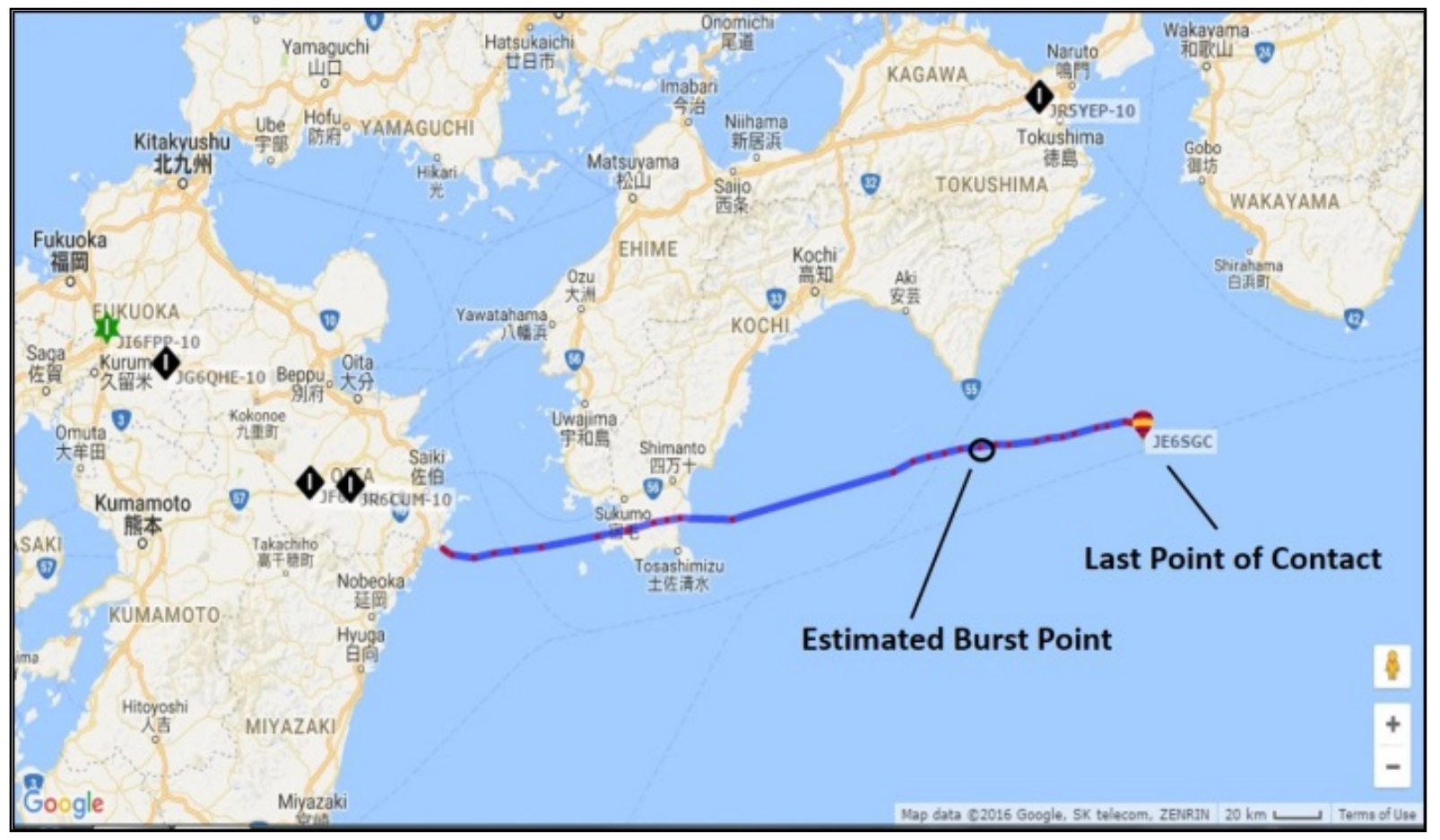

Figure 19. Last Point of Contact for Balloon System

During that time, the payload was in the descending phase. It was predicted that the payload might splashdown near the Kii Peninsular before drifting to the peninsular coastline, east of the last point of contact. This prediction was based on data of the ocean current movement during launch day. Figure 20 illustrates the Kuroshio ocean current information during the launch day. Figure 20 showed that the current flowed past Kyushu islands then towards Kochi area before heading to the Kii Peninsular. 


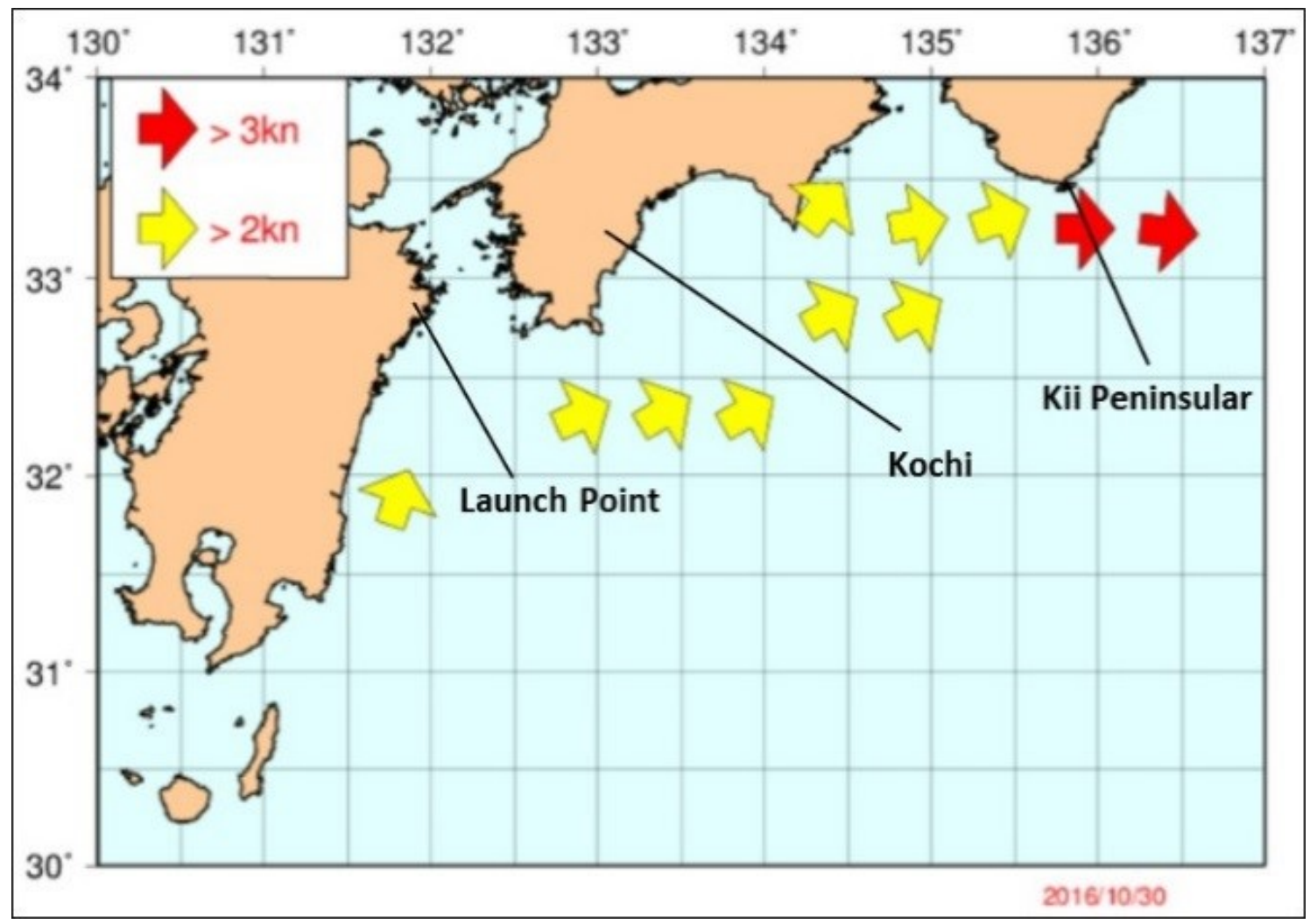

Figure 20. Kuroshio Ocean Current Information

The recovery team was not able to search for the payload during launch day due to the big difference between actual and estimated recovery point. Notifications were submitted to universities and other related organizations near the Wakayama coastline regarding the payload. It is hoped that the notified parties or the public may recover and notify KIT about the payload.

\subsection{Altitude}

Data from APRS was also used to plot the change in altitude and velocity during the flight. The predicted burst point was at $20 \mathrm{~km}$ compared to approximately $12 \mathrm{~km}$ for the actual data. A possible reason was the early balloon explosion due to leakage from an expanding small hole.

The balloon maintained a near stable altitude for approximately 40 minutes between an altitude of $11 \mathrm{~km}$ to $12 \mathrm{~km}$. Theoretically, a lower burst altitude of $12 \mathrm{~km}$ should have resulted in a shorter flight. However, the total flight duration was approximately 2 hours 20 minutes until the last point of contact. In comparison, the predicted flight duration was approximately 1 hour 50 minutes. The long drift period between $11 \mathrm{~km}$ and $12 \mathrm{~km}$ may have contributed to the extended flight duration compared to the predicted flight duration. Figure 21 illustrates the change in altitude, horizontal velocity and vertical velocity during the flight.

The predicted altitude assumed a steady ascent velocity of $4.15 \mathrm{~m} / \mathrm{s}$ and an average descent velocity of $6 \mathrm{~m} / \mathrm{s}$. In addition, the predicted values do not take into account the effect of weather. Based on the APRS data, average ascent velocity was $2.6 \mathrm{~m} / \mathrm{s}$ and the average descent velocity was $5 \mathrm{~m} / \mathrm{s}$. Strong winds could have affected the ascent velocity. Based on Figure 21, the horizontal velocity of the balloon was increasing until burst point. The horizontal velocity was as high as $80 \mathrm{~m} / \mathrm{s}$ or $290 \mathrm{~km} / \mathrm{h}$ which may explain the presence of strong wind patterns such as the jet stream. In terms of vertical velocity, the velocity decreased at a slow rate before remaining stable at altitudes between $11 \mathrm{~km}$ to $12 \mathrm{~km}$. This agrees with the earlier discussion on the stable range of altitude maintained by the balloon. The vertical velocity increased substantially after the bursting point before gradually slowing down. A gradual decreased in descent velocity may explain the successful deployment and working of the parachute. 


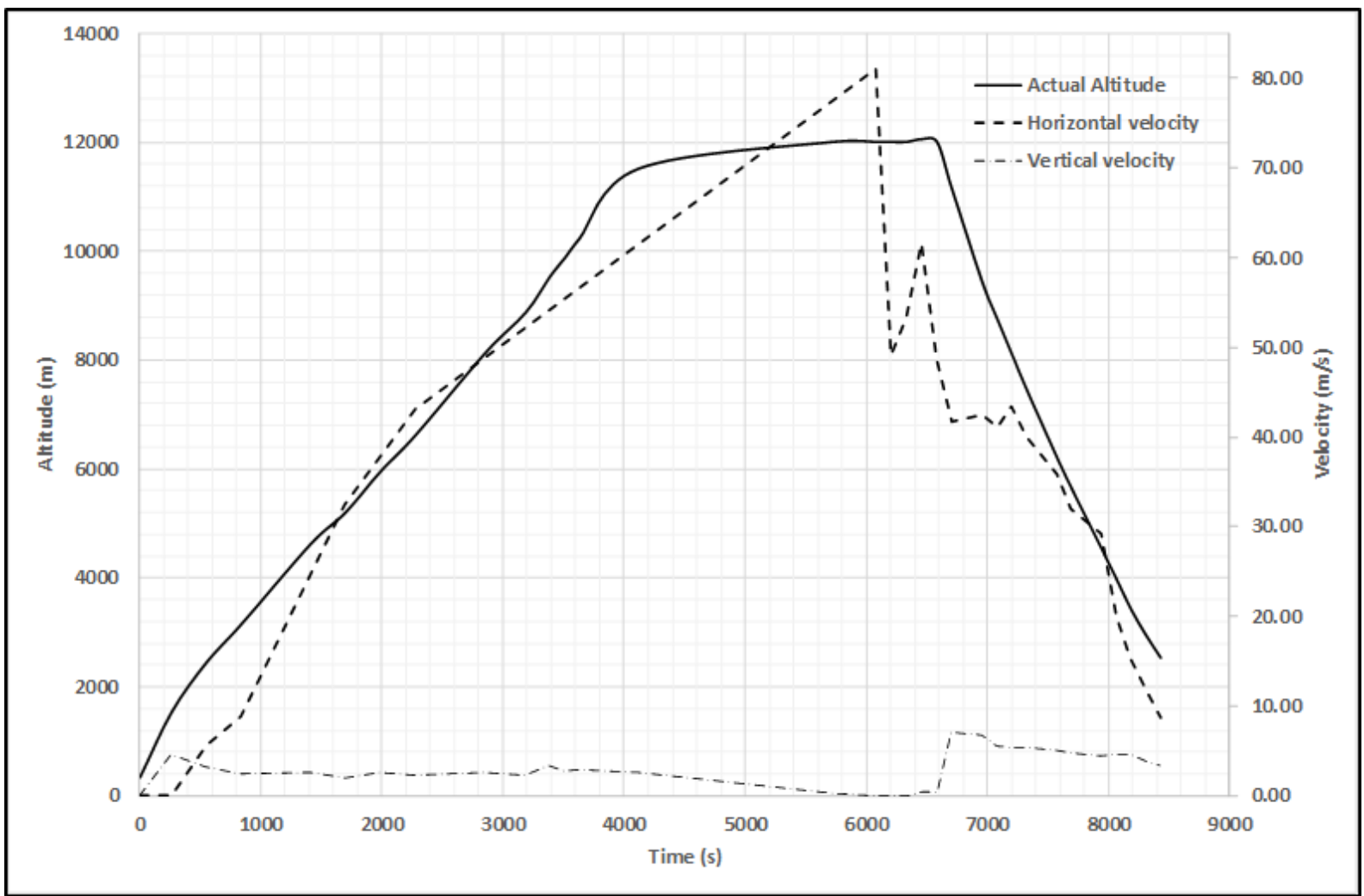

Figure 21. Change in Altitude, Vertical Velocity and Horizontal Velocity during Flight

\section{Discussions}

The possible factors for the difference between actual and predicted flight path are listed below:

i Stronger than predicted wind patterns may have caused the balloon system to drift further during ascend and descend.

ii The descent velocity was slower than the estimated value.

iii A small hole was detected during the inflation process. Even though the hole was covered with duct tape, the expanding balloon may have expanded the hole resulting in a lower burst altitude of $12 \mathrm{~km}$ instead of $20 \mathrm{~km}$.

iv Accidental disconnection of wiring within the tracking subsystem due vibration.

The above factors may have led to the non-recovery of the payload. Based on this project and the mentioned factors, more emphasis needs to be put on recovering the payload. The success of the primary objectives depends on the ability to recover the payload. A list of the proposed solutions to improve payload recovery is listed below:

i Usage of a balloon that is used for meteorological missions such as those manufactured by Totex. Totex is a Japanese manufacturer of meteorological balloons. These balloons tend to have better build quality thus avoiding holes from developing during the inflation process.

ii The decision on determining the suitable launch day can be improved by incorporating accurate weather forecasts including forecasted jet stream movements and to performed flight prediction for a variety of scenarios.

iii More practice of the launch procedure should be performed to avoid mistakes during the launch day itself.

iv To perform a drop test with a full electrical system as payload in order to test the reliability of the electrical connections.

A future launch has been proposed that may incorporate the above mitigation proposals. The next launch date will tentatively be from $21^{\text {st }}$ to $29^{\text {th }}$ January 2017 . The launch location will be from Tsushima (Nagasaki) or Saiki (Oita) in Japan.

\section{Conclusions}

Global warming has been a major concern around the world. Further research on the ozone layer and greenhouse gases is important in order to understand global warming. This project will help in the understanding of global warming. The project mission objectives are listed below:

i To obtain video of the Earth's surface and space. 
ii To perform in-situ measurement for the concentration of Ozone $\left(\mathrm{O}_{3}\right)$ and Carbon Dioxide $\left(\mathrm{CO}_{2}\right)$ gas in the stratosphere.

This project was part of the project-based learning (PBL) course in KIT. The balloon was launch on 30/10/2016 from Saiki in the Oita prefecture of Kyushu, Japan. The balloon ascended until $12 \mathrm{~km}$ before it burst. The payload then descended to the sea using a parachute. The estimated landing spot was near the Kochi prefecture in Shikoku, Japan.

The payload structure was made from EPS polystyrene with a cylindrical shape. The thermal control system of the structure consisted of a polystyrene structure and polyester film with aluminum vacuum deposition coating on the inside wall. A thermal analysis was performed to determine the effectiveness of the thermal control system during flight. A latex balloon was used to lift the structure. An excel based burst calculator was used to predict the burst altitude and the volume of helium required before launch. The parachute was constructed from silnylon. Several drop tests were performed to confirm the feasibility of the parachute and connection design. The payload consisted of an electrical system divided into three subsystems which were the sensor, tracking and imaging subsystem. The sensor subsystem provides pressure, internal temperature, ozone, and carbon dioxide gas concentration data. The tracking and imaging subsystem provides real-time position, altitude, and video data.

At the present date, the payload has not been recovered yet. The only available data obtained were the location and altitude data. The last data obtained was at an altitude of approximately $2,500 \mathrm{~km}$ above sea level. The payload was predicted to drift to the Kii Peninsular. Overall this article will serve as a useful reference for future HAB missions.

\section{REFERENCES}

[1] New Mexico Solar Energy Association, Global Warming
FAQ, Online available from http://www.nmsea.org/Curriculum/Primer/Global_Warmin g/fossil_fuels_and_global_warming.htm

[2] Goodwin, D., Global Warming For Beginners 2008., For Beginners LLC, CT, 2008.

[3] US Environmental Protection Agency, The Greenhouse Effect, Online available from https://www3.epa.gov/climatechange/kids/basics/today/gree nhouseeffect.

[4] Liang, J., 2013. Chemical composition of the atmosphere of the Earth. In: Chemical Modeling for Air Resources: Fundamentals, Applications, and Corroborative Analysis. s.1.:Academic Press, pp. 3-20.

[5] Brand, R., UpLift-1 Facts and Figures 28th Dec 2011 Pt3, Online available from http://wotzup.com/2013/09/uplift1 flightdatapt3archives/\#

[6] eFluid, Drag of Blunt Bodies and Streamlined Bodies, Online available from https://www.princeton.edu/ asmits/Bicycle web/blunt.html

[7] NASA Glenn Research Center, Shape Effects on Drag, Online available from https://www.grc.nasa.gov/www/k-12/airplane/shaped.html

[8] Turtle Mountain Community College, Reflectivity in Remote Sensing, Online available from http://sti.usra.edu/TRESTE/07_annual_workshop_presentat ions/07workshop_docs/07workshop_TMCC/Reflectivity\% 20 in $\% 20$ Remote $\% 20$ Sensing\% $\%$ - $\% 20$ student $\% 20$ version. pdf

[9] AIMCAL, Metallizing Technical Reference, Online available from http://www.aimcal.org/uploads/4/6/6/9/46695933/aimcal-m etallizing-technical-reference-5thed.pdf

[10] Randall, S., Totex Balloon Burst Estimator - Near Space Ballooning, Online available from www.nearspaceballooning.com/files/burst3.xls

[11] Verhage, P., Near Space Exploration with the BASIC Stamp, Parallax Inc, 2005.

[12] Bruninga, B., Automatic Packet Reporting System, Online available from http://www.aprs.org/ 